\title{
Corrigendum: Data practices and inequality in South African early childhood development policy: Technocratic management versus social transformation
}

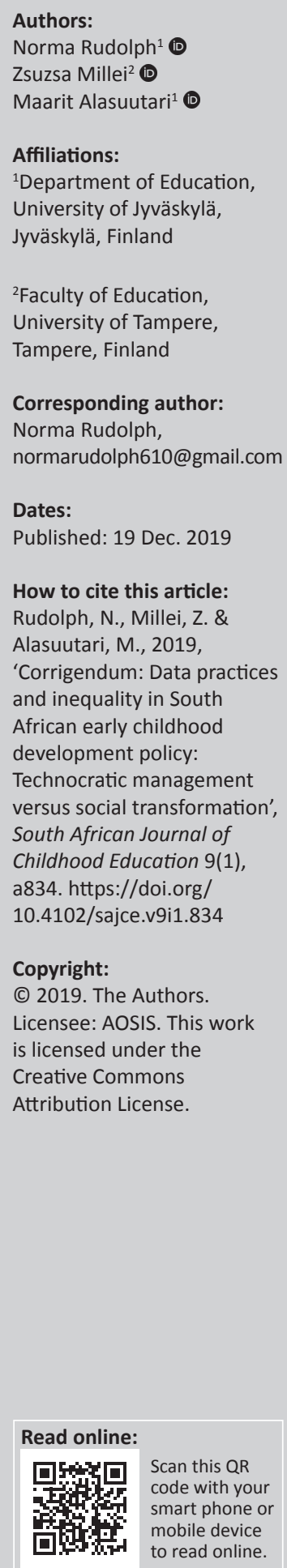

In the version of this article published earlier, the name of the second author, Zsuzsa Millei, was inadvertently misspelt as 'Zsuzsanna Millei'. The second author's name should have appeared as 'Zsuzsa Millei' throughout the author list and 'How to cite' information section. This correction does not alter the study's findings of significance or overall interpretation of the study results. 